\title{
Scintigraphic comparison of budesonide deposition from two dry powder inhalers
}

\author{
S.P. Newman*, G.R. Pitcairn*, P.H. Hirst*, R.E. Bacon*, E. O'Keefe**, M. Reiners**, R. Hermann**
}

Scintigraphic comparison of budesonide deposition from two dry powder inhalers. S.P. Newman, G.R. Pitcairn, P.H. Hirst, R.E. Bacon, E. O'Keefe, M. Reiners, R. Hermann. (C) ERS Journals Ltd 2000.

ABSTRACT: Chlorofluorocarbons (CFCs), used in metered dose inhalers (MDIs), have been identified as being deleterious to the environment leading to a ban on their production. Dry powder inhalers (DPIs) are a widely used alternative to MDIs. One disadvantage of DPIs is that in vivo lung deposition can be influenced by the patient's inspiratory flow rate. The ASTA Medica multi-dose dry powder inhaler (AM-MDPI) has been designed to offer low resistance on inhalation, so that asthmatic patients can achieve inhaled flow rates of $\sim 90 \mathrm{~L} \cdot \mathrm{min}^{-1}$.

The aim of the study was to evaluate the in vivo deposition of budesonide from the AM-MDPI at different flow rates and to compare this with delivery from a Turbuhaler DPI at a high flow rate. The study was a scintigraphic, randomized, crossover study in which 13 healthy volunteers inhaled a single $200 \mu \mathrm{g}$ dose of radiolabelled budesonide on four separate occasions with a minimum 44-h washout period between dosings.

At the lowest flow rate of $54 \mathrm{~L} \cdot \mathrm{min}^{-1}$, comparable to that for the Turbuhaler (58 $\mathrm{L} \cdot \mathrm{min}^{-1}$ ), a similar percentage of the metered dose was delivered to the lung (AMMDPI median 19.9\%; Turbuhaler median $21.4 \%$ ). At high flow rate (peak inspiratory flow rate $99 \mathrm{~L} \cdot \mathrm{min}^{-1}$ ) the AM-MDPI delivered significantly more drug to the lung (median $32.1 \%$ of metered dose) than at $65 \mathrm{~L} \cdot \mathrm{min}^{-\mathrm{P}}$ or $54 \mathrm{~L} \cdot \mathrm{min}^{-1}$ (median $25.0 \%$ and $19.9 \%$ of metered dose, respectively), thus demonstrating flow rate dependence. The pattern of regional lung deposition from the AM-MDPI was similar for all three inhalation manoeuvres.

It was concluded that the ASTA Medica multi-dose dry powder inhaler achieves at least as much deposition of budesonide in the lungs as a Turbuhaler when used at similar inspiratory flow rates.

Eur Respir J 2000; 16: 178-183.

For many years, chlorofluorocarbon (CFC)-propelled pressurized metered-dose inhalers (MDIs) have been used to deliver therapeutic aerosols to the respiratory tract of asthmatic patients. However, in recent years CFCs have been identified as being deleterious to the environment leading to a ban on their production throughout most of the world. Alternative devices include dry powder inhalers (DPIs), via which metered amounts of powder are entrained in a stream of air drawn through the inhaler by the patients own inspiratory flow.

One of the benefits of DPIs is that breath actuation precludes the need for the patient to coordinate actuation with inhalation; a problem associated with suboptimal drug delivery from MDIs. However, a significant disadvantage of DPIs is that in vivo deposition can be influenced by the patient's inspiratory flow rate $[1,2]$. A new DPI, the ASTA Medica multi-dose dry powder inhaler (AM-MDPI; ASTA Medica AG, Frankfurt-am-Main, Germany), has been designed to offer low resistance on inhalation so that asthmatic patients can achieve flow rates of $\sim 90 \mathrm{~L} \cdot \mathrm{min}^{-1}$, through the device [3]. In clinical practice, however, the device may be used by patients with severe asthma and its performance at lower flow rates is therefore also of clinical
*Pharmaceutical Profiles Ltd., Ruddington, Nottingham, UK. **Corporate Research, ASTA Medica AG, Frankfurt-am-Main 1, Germany.

Correspondence: S.P. Newman

Pharmaceutical Profiles Ltd.

Mere Way

Ruddington Fields

Ruddington

Nottingham NG11 6JS

UK

Fax: 441159748000

Keywords: Budesonide

dry powder inhaler

gamma scintigraphy

total and regional lung deposition

Received: July 131999

Accepted after revision March 72000

The project was supported by ASTA Medica AG, Frankfurt-am-Main, Germany. relevance. The present study aimed to evaluate the delivery of budesonide from the AM-MDPI at different flow rates, using a well validated gamma scintigraphic technique [46] and to compare this with delivery from a Turbuhaler dry powder inhaler (Astrazeneca, Lund, Sweden) used at a high flow rate.

\section{Materials and methods}

\section{ASTA Medica multi-dose dry powder inhaler}

The AM-MDPI (fig. 1) consists of an injection moulded device containing a refillable cartridge [3]. A metered dose is loaded into the inhalation channel (by volumetric means) when a button on top of the device is depressed. A window on the front of the inhaler changes from blue to green to indicate that a dose is ready for inhalation.

\section{Subjects}

Fourteen healthy volunteers (seven male, seven female) aged 18-60 yrs were studied. All subjects had normal respiratory function with values for forced expiratory volume in one second (FEV1), peak expiratory flow rate 


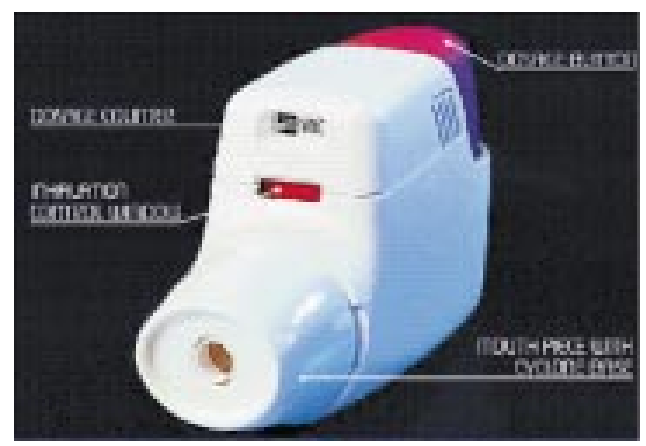

Fig. 1. - Diagram of the ASTA Medica multi-dose dry powder inhaler.

(PEFR) and forced vital capacity (FVC) $>80 \%$ of the predicted value for their age, sex, height and race [7]. Prior to enrolment, the nature of the study was fully explained to each volunteer and written informed consent to participation obtained. The study was approved by the Quorn Research Review Committee, Leicestershire, UK, and the administration of radioactive aerosols approved by the UK Department of Health. The study was performed in accordance with the Declaration of Helsinki.

\section{Study design}

A single $(200 \mu \mathrm{g})$ dose of radiolabelled budesonide was administered from either a Turbuhaler, at a targeted peak inspiratory flow rate (PIFR) of $60 \mathrm{~L} \cdot \mathrm{min}^{-1}$, or the AMMDPI at targeted PIFRs of 45,60 or $90 \mathrm{~L} \cdot \mathrm{min}^{-1}$, in a randomized crossover fashion on four study days separated by a minimum of $44 \mathrm{~h}$. Inhalation flow rates, inhaled volumes and breathholding pauses (targeted value $10 \mathrm{~s}$ ) were monitored by a Vitalograph MDI-Compact Spirometer(Vitalograph Ltd., Maids Moreton, Buckinghamshire, UK), connected in series with the inhaler devices. Inhalation flow rates of $60 \mathrm{~L} \cdot \mathrm{min}^{-1}$ for Turbuhaler, and $90 \mathrm{~L} \cdot \mathrm{min}^{-1}$ for AM-MDPI, represented maximal inspiratory effort for each device.

\section{Radiolabelling of the powder formulations}

Budesonide from the Turbuhaler was radiolabelled using the method described by Thorsson et al. [8]. Briefly, the radiolabel $\left({ }^{99 \mathrm{~m}} \mathrm{Tc}\right)$ was extracted from the aqueous phase into methyl-ethyl-ketone which was subsequently evaporated. The radiolabel was then redissolved in water and mixed with the budesonide powder. After removing the water by freeze drying the radiolabelled powder was put into an empty Turbuhaler. The radiolabelling method used for the AM-MDPI was broadly based upon methods developed for other drug/lactose powder blends [9, 10]. Budesonide was labelled as described for the Turbuhaler, an appropriate mass of lactose added, and a Turbula 2TC mixer (Glencreston, Stanmore, UK) used to prepare a homogenous powder blend. A cartridge was filled with powder formulation and placed in an AM-MDPI device. Each metered dose from the Turbuhaler and AM-MDPI contained $200 \mu \mathrm{g}$ of budesonide and $\leq 10 \mathrm{MBq}$ of ${ }^{99 \mathrm{~m}} \mathrm{Tc}$. The maximum radiation dose to each volunteer over the four study days was estimated to be $0.61 \mathrm{mSv}$.

In vitro particle sizing experiments were conducted using a five stage high precision multistage liquid impinger, to demonstrate that the radiolabel was a valid marker for the drug and that the radiolabelling process did not adversely affect the size distribution of the drug [11]. The impinger was operated at a flow rate corresponding to a pressure drop of $4 \mathrm{kPa}$; the flow rates used for the Turbuhaler and AM-MDPI were 60 and $80 \mathrm{~L} \cdot \mathrm{min}^{-1}$, respectively. A fixed volume of air (4 L) was drawn through the inhaler devices during each test. The fine particle fraction (FPF), calculated as the percentage of the drug or radiolabel recovered from stages 3,4 and 5 , and the fine particle dose (FPD), i.e. the mass of drug recovered from stages 3, 4 and 5, were determined.

\section{Gamma scintigraphy}

Immediately after administration of the radiolabelled formulation, posterior and anterior views of the lungs and stomach $(100 \mathrm{~s})$, and a right lateral view of the oropharynx (30 s) were recorded using a gamma camera (General Electric Maxicamera, Milwaukee, WI, USA) connected to a Bartec Micas V computer system (Nodacrest Ltd, Byfleet, UK). Scintigraphic images of the AM-MDPI device, with cartridge removed, but including mouthpiece and inhalation channel, the Turbuhaler mouthpiece and exhalation filter were also recorded to allow for quantification of deposition outside the body. On one study day a posterior lung ventilation scan using the radioactive inert gas ${ }^{81 \mathrm{~m}} \mathrm{Kr}$ was performed on each volunteer to define the edges of the lung fields. Counts from each region were corrected for background radioactivity, radioactive decay, and for tissue attenuation of gamma rays [12]. The geometric means of anterior and posterior lung and stomach counts were calculated.

The counts in each region were expressed as percentages of the sum of the total body counts and those deposited on the AM-MDPI device or the Turbuhaler mouthpiece, and on the exhalation filter. This enabled calculation of the percentages of dose in the whole lung and oropharynx (including the stomach and oesophagus), retained on the AMMDPI mouthpiece and Turbuhaler mouthpiece, and recovered from the exhaled air. The lungs were subdivided into central, intermediate and peripheral regions of interest as previously described [13], thus enabling the percentage of the dose in each lung zone to be determined and the peripheral zone/central zone deposition ratio $(\mathrm{P} / \mathrm{C}$ ratio) to be calculated [13].

A Vitalograph Compact spirometer (Vitalograph Ltd., Maids Moreton, Buckinghamshire, UK) was used to record FEV1, PEFR and FVC prior to dosing and then 60 min later.

Differences in deposition patterns for the two devices were analysed statistically by means of the Wilcoxon matched-pairs signed-ranks test; a p-value of $\leq 0.05$ was considered significant. One subject missed dosing on one occasion and hence the data for the remaining three dosings administered to this subject were omitted from the statistical analysis.

\section{Results}

\section{Radiolabelling validation}

The results of the radiolabelling validation experiments are shown on table 1. Data for the mouthpiece, throat and stage 1 were combined due to small mismatches observed between the drug and radiolabel; this was not considered 
Table 1. - Radiolabelling validation data for the ASTA Medica multi-dose dry powder inhaler (AM-MDPI; ASTA Medica AG, Frankfurt-am-Main, Germany $n=3$ ) and for Turbuhaler $(n=5)$ showing distributions of drug before labelling, drug after labelling and radiolabel in a multistage liquid impinger

\begin{tabular}{lrrr}
\hline & $\begin{array}{c}\text { Drug before } \\
\text { radiolabelling }\end{array}$ & \multicolumn{1}{c}{$\begin{array}{c}\text { Drug after } \\
\text { radiolabelling }\end{array}$} & Radiolabel \\
\hline AM-MDPI & & & \\
Throat, Mouth- & & & \\
piece \& Stage 1 & $60.6 \pm 0.4$ & $62.2 \pm 3.1$ & $60.9 \pm 2.1$ \\
Stage 2 & $3.9 \pm 1.1$ & $4.3 \pm 0.8$ & $3.4 \pm 0.4$ \\
Stage 3 & $7.5 \pm 2.5$ & $10.5 \pm 1.7$ & $9.4 \pm 2.1$ \\
Stage 4 & $14.5 \pm 2.3$ & $12.9 \pm 1.7$ & $13.2 \pm 1.2$ \\
Stage 5 & $13.6 \pm 0.9$ & $10.1 \pm 2.1$ & $13.0 \pm 1.6$ \\
Turbuhaler & & & \\
Throat, Mouth- & & & \\
piece \& Stage 1 & $59.4 \pm 1.4$ & $53.0 \pm 5.1$ & $60.2 \pm 3.3$ \\
Stage 2 & $4.4 \pm 0.9$ & $8.5 \pm 8.1$ & $4.9 \pm 1.4$ \\
Stage 3 & $10.6 \pm 1.3$ & $13.3 \pm 1.1$ & $11.4 \pm 1.1$ \\
Stage 4 & $14.0 \pm 0.5$ & $14.7 \pm 2.1$ & $13.0 \pm 2.3$ \\
Stage 5 & $11.6 \pm 1.1$ & $10.5 \pm 1.9$ & $10.5 \pm 1.7$ \\
\hline
\end{tabular}

Data are expressed as mean \pm SD percentage distributions of drug and radiolabel within the impinger. The impinger collects particles on a $90^{\circ}$ inlet "throat" and on five stages representing particle fractions of steadily decreasing size.

important as these combined stages represent particles $>11 \mu \mathrm{m}$ and so would be expected to deposit mainly in the oropharynx. For the Turbuhaler, there was a very good match between the size distributions of drug before labelling, drug after labelling and the radiolabel on the remaining stages, mean \pm SD FPFs were $36.2 \pm 1.0 \%, 38.5 \pm$ $4.9 \%$ and $35.0 \pm 4.5 \%$, respectively. There was a good match between the mass of drug in the fine particle range before and after labelling; mean \pm SD FPDs were $76.6 \pm$ $6.4 \mu \mathrm{g}$ and $77.9 \pm 7.7 \mu \mathrm{g}$, respectively. Equally good data were obtained for the AM-MDPI; mean \pm SD FPFs were $35.5 \pm 0.7 \% 33.3 \pm 3.4 \%$ and $35.6 \pm 2.2 \%$, for drug before labelling, drug after labelling and radiolabel, respectively. Similarly, there was a good match between the mass of drug in the fine particle range before and after labelling; mean \pm SD FPDs were $68.3 \pm 1.3 \mu \mathrm{g}$ and $67.9 \pm 4.2 \mu \mathrm{g}$, respectively. On the basis of these data it was concluded that the radiolabel would be a valid marker for the drug and that the radiolabelling process had not changed the particle size distribution of the product.

\section{Inhalation manoeuvres and lung function}

Details of the inhalation manoeuvres are displayed in table 2. The mean PIFRs for the AM-MDPI were 99 $\mathrm{L} \cdot \mathrm{min}^{-1}\left(\right.$ target $\left.90 \mathrm{~L} \cdot \mathrm{min}^{-1}\right) ; 65 \mathrm{~L} \cdot \mathrm{min}^{-1}\left(\right.$ target $\left.60 \mathrm{~L} \cdot \mathrm{min}^{-1}\right)$ and $54 \mathrm{~L} \cdot \mathrm{min}^{-1}\left(\right.$ target $\left.45 \mathrm{~L} \cdot \mathrm{min}^{-1}\right)$ and for the Turbuhaler, $58 \mathrm{~L} \cdot \mathrm{min}^{-1}\left(\right.$ target $\left.60 \mathrm{~L} \cdot \mathrm{min}^{-1}\right)$. Mean breathholding times and inhaled volumes were comparable for all four dosing regimens. Respiratory function measurements before and $60 \mathrm{~min}$ postdosing showed no significant changes following any of the dosing regimens (table 2).

\section{Deposition data}

Scintigraphic images obtained using the AM-MDPI and Turbuhaler are shown in figure 2 . The median percentage of metered dose delivered to the whole lung by the AM-
MDPI was dependent on PIFR, as shown in table 3, being $32.1 \%, 25.0 \%$ and $19.9 \%$ for targeted flow rates of 90,60 and $45 \mathrm{~L} \cdot \mathrm{min}^{-1}$, respectively $(\mathrm{p}=0.002)$. For the Turbuhaler at $60 \mathrm{~L} \cdot \mathrm{min}^{-1}$ median percentage whole lung deposition was $21.4 \%$. The AM-MDPI at the two higher flow rates delivered a significantly higher percentage of the metered dose to the whole lung than the Turbuhaler $(\mathrm{p}=$ 0.02 and $p=0.03$ at targeted PIFRs of 90 and $60 \mathrm{~L} \cdot \mathrm{min}^{-1}$, respectively). Deposition from the AM-MDPI in each of the central, intermediate and peripheral lung regions increased with increasing PIFR. The Peripheral lung zone/ Central lung zone $(\mathrm{P} / \mathrm{C})$ ratio was similar for all dosing regimens of the AM-MDPI, and for the Turbuhaler.

Oropharyngeal deposition was similar for all three AMMDPI flow rates, whereas the Turbuhaler deposited more drug in the oropharynx (table 3 ). There was significantly greater oropharyngeal deposition with the Turbuhaler compared to the AM-MDPI at $60 \mathrm{~L} \cdot \mathrm{min}^{-1}$ and $45 \mathrm{~L} \cdot \mathrm{min}^{-1}$ $(\mathrm{p}=0.01$ and $\mathrm{p}=0.02$, respectively). The median percentage of dose retained on the AM-MDPI mouthpiece ranged from $9.5 \%$ at a targeted flow rate of $90 \mathrm{~L} \cdot \mathrm{min}^{-1}$ to $17.3 \%$ at a targeted flow rate of $45 \mathrm{~L} \cdot \mathrm{min}^{-1}$ (table 3 ). For the Turbuhaler, $11.6 \%$ of the dose (median) was deposited on the mouthpiece. Relatively little drug was deposited on the exhalation filter following any of the dosing regimens.

\section{Discussion}

This scintigraphic study has shown that a novel multidose dry powder inhaler (AM-MDPI) deposits at least as much budesonide in the lungs as a Turbuhaler, when used at similar peak inhaled flow rates.

The Montreal protocol banning the use of CFC propellants has been a major stimulus to the development of novel inhaler technologies for asthma therapy, including many new DPIs [14]. Each of these new devices is unique in its drug delivery characteristics. These differences between products, and especially drug delivery relative to the devices which are currently most widely used, such as the Turbuhaler, need to be documented. This reflects a perceived need, best summed up in comments made by KeELEY and ReES [15] in relation to the recent British Thoracic Society guidelines on asthma therapy [16]. KEELEY and REES [15] commented that, "As the range of inhaler devices increases, the information on their lung deposition and delivery does not seem to expand in parallel" and that, "Devices cannot be changed on the assumption that the same dose will be delivered to the patient's airways, and prescribers must be aware of the delivery characteristics of any device they prescribe". Lung deposition studies thus seek to provide key data documenting drug delivery in vivo for novel and established products.

The deposition of asthma drugs in the lungs is closely linked to their subsequent clinical effects [17-19], since inhaled asthma drugs must be deposited in sufficient quantity if they are to be effective. Drugs are better targeted to the required site of action using devices which deposit a relatively high percentage of the dose in the lungs, and this could result in an improved therapeutic ratio for inhaled asthma drugs. These benefits are especially important for inhaled corticosteroids, which can lead to significant systemic side-effects when used in 
Table 2. - Details of the inhalation manoeuvre and pre- and 60 min postdosing forced expiratory volume in one second (FEV1) measurements for studies with the ASTA Medica multi-dose dry powder inhaler (AM-MDPI; ASTA Medica AG, Frankfurt-am-Main, Germany) and Turbuhaler

\begin{tabular}{lcccc}
\hline & AM-MDPI & AM-MDPI & AM-MDPI & Turbuhaler \\
\hline Targeted PIFR L·min ${ }^{-1}$ & 90 & 60 & 45 & 60 \\
Measured PIFR L·min & $99 \pm 13$ & $65 \pm 3$ & $54 \pm 7$ & $58 \pm 6$ \\
Inhaled volume L & $3.13 \pm 1.01$ & $2.96 \pm 0.83$ & $2.77 \pm 0.97$ & $2.61 \pm 0.63$ \\
Breath hold s & $9.7 \pm 0.5$ & $10.5 \pm 2.8$ & $10.0 \pm 1.0$ & $10.1 \pm 0.8$ \\
Predose FEV1 L & $3.31 \pm 0.58$ & $3.30 \pm 0.62$ & $3.25 \pm 0.59$ & $3.36 \pm 0.63$ \\
Postdose FEV1 L & $3.39 \pm 0.57$ & $3.41 \pm 0.60$ & $3.43 \pm 0.63$ & $3.41 \pm 0.56$ \\
\hline
\end{tabular}

Data are expressed as mean \pm SD. PIFR: peak inspiratory flow rate.

sufficiently high doses [20]. The data generated in this study which quantified the relative lung depositions from AM-MDPI and Turbuhaler were used in order to confirm the relative doses to be administered from each device in a subsequent multi-centre phase III clinical trial comparing the two devices in parallel groups of 150 subjects.

The AM-MDPI deposited at least as much budesonide in the lungs of healthy volunteers as the Turbuhaler DPI.
However, several previous deposition studies have been performed using the Turbuhaler, using either gamma scintigraphy or the charcoal block pharmacokinetic technique [4] and mean deposition values ranging from 14\% [21] to $32 \%$ [22] of the metered dose with optimal inhaler technique have been found. This variability in lung deposition observed for the Turbuhaler does not appear to depend on which method was used to assess deposition, or upon a)

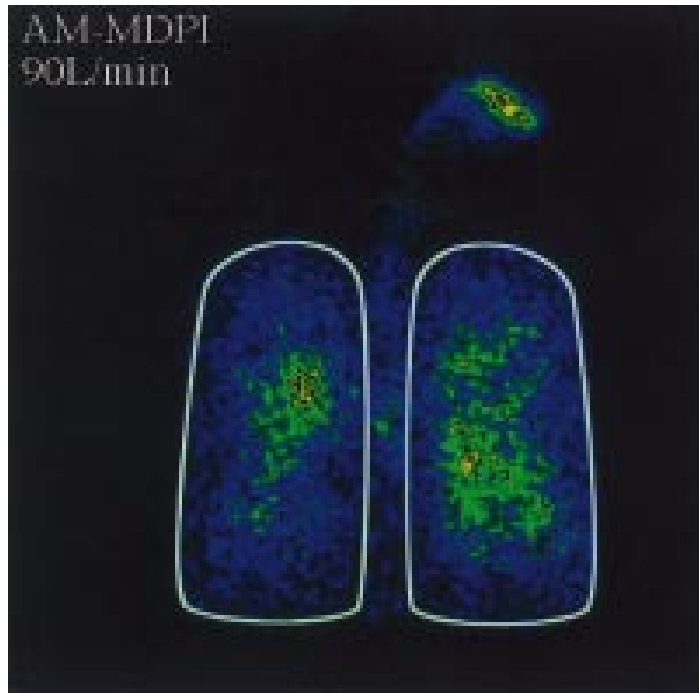

c)

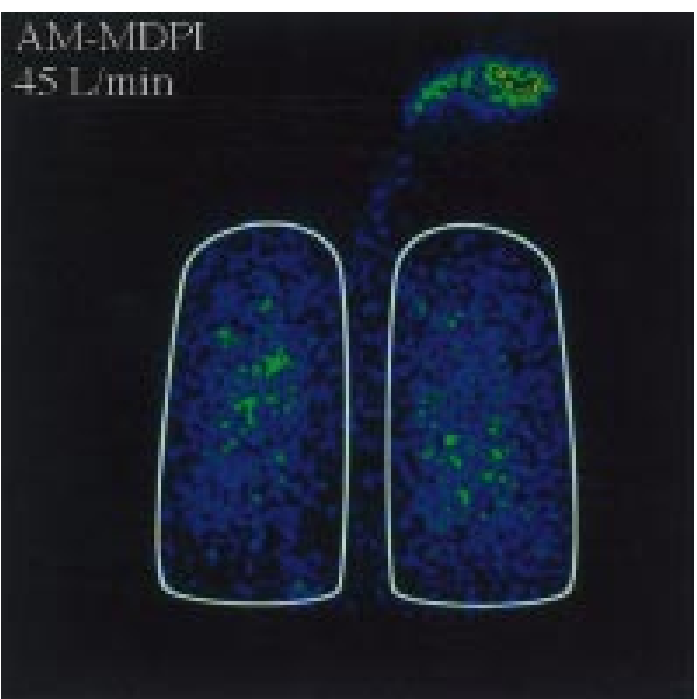

b)

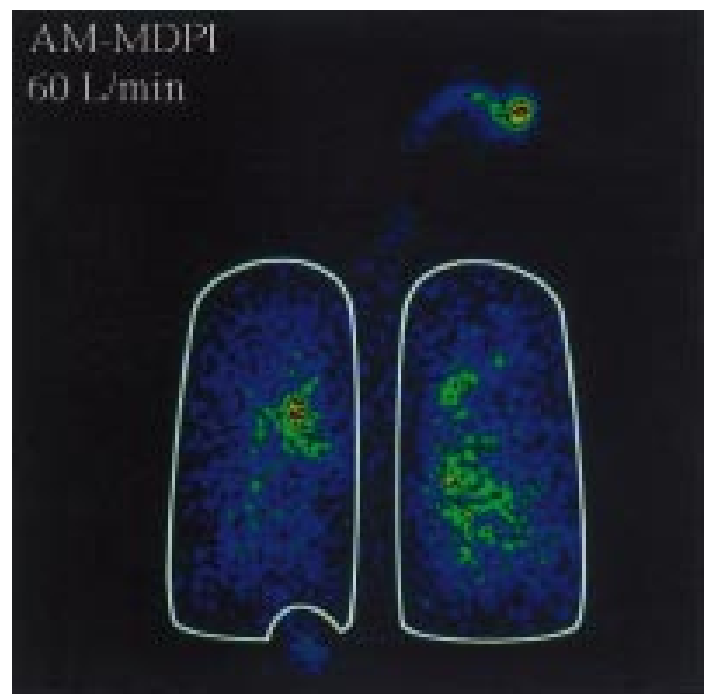

d) Trubulaler

60 Limin

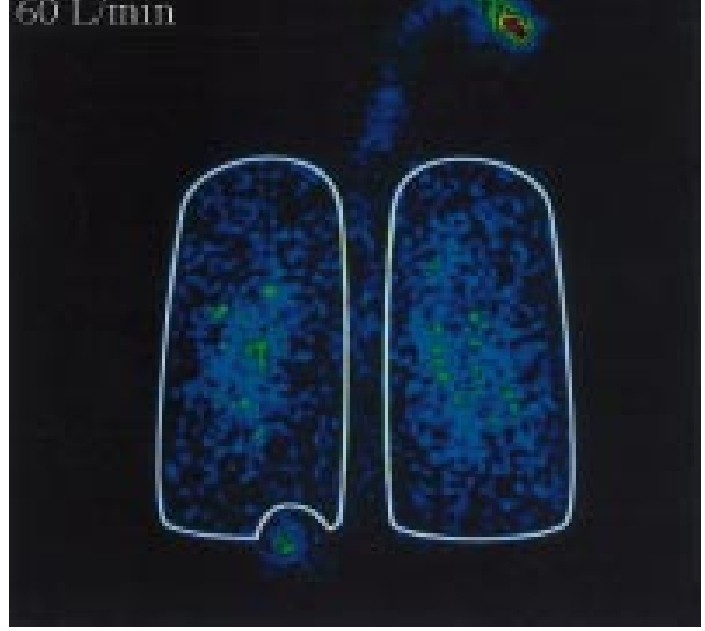

Fig. 2. - Scintigraphic images obtained using the ASTA Medica multi-dose dry powder inhaler (AM-MDPI; ASTA Medica AG, Frankfurt-am-Main, Germany) at targeted inhaled flow rates of: a) $90 \mathrm{~L} \cdot \mathrm{min}^{-1}$; b) $60 \mathrm{~L} \cdot \mathrm{min}^{-1}$; c) $45 \mathrm{~L} \cdot \mathrm{min}^{-1}$; and d) the Turbuhaler at a targeted inhaled flow rate of $60 \mathrm{~L} \cdot \mathrm{min}^{-1}$. 
Table 3. - Deposition data for the ASTA Medica multi-dose dry powder inhaler (AM-MDPI; ASTA Medica AG, Frankfurtam-Main, Germany) and Turbuhaler. Deposition on the device mouthpiece, and exhalation filter and in the oropharynx and lungs are expressed as percentages of the metered dose

\begin{tabular}{lcccc}
\hline & AM-MDPI & AM-MDPI & AM-MDPI & Turbuhaler \\
\hline Targeted PIFR L·min & -1 & 60 & 45 & 60 \\
Measured PIFR L·min & & 65 & 58 \\
Mouthpiece & 90 & $15.6(1.2-20.0)$ & $17.3(11.8-43.0)$ & $11.6(5.3-22.0)$ \\
Exhalation filter & $9.5(5.5-23.2)$ & $0.6(0.2-3.0)$ & $0.2(0-0.9)$ & $0.2(0-0.7)$ \\
Oropharynx & $0.8(0.2-1.8)$ & $61.6(42.2-77.6)$ & $60.9(49.5-68.3)$ & $71.9(54.8-80.0)$ \\
Lungs & $57.0(45.1-81.7)$ & $25.0(12.1-37.4)$ & $19.9(8.8-26.6)$ & $21.4(4.7-29.2)$ \\
Central lung & $32.1(9.4-41.0)$ & $7.8(3.7-11.8)$ & $6.3(2.3-8.4)$ & $5.9(1.7-10.0)$ \\
Intermediate lung & $10.6(3.0-13.4)$ & $8.9(4.6-12.2)$ & $6.7(3.2-9.9)$ & $7.3(3.2-11.0)$ \\
Peripheral lung & $10.9(3.8-15.9)$ & $7.8(3.7-13.4)$ & $6.5(3.4-8.8)$ & $4.8(2.5-9.1)$ \\
Peripheral/central zone ratio & $8.5(2.5-13.4)$ & $1.0(0.8-1.3)$ & $1.0(0.7-1.5)$ & $0.9(0.5-1.6)$ \\
\hline
\end{tabular}

Data are expressed as percentages (unless otherwise indicated) in medians with ranges in parentheses. PIFR: peak inspiratory flow rate.

whether healthy volunteers or patients with asthma were studied. Mean lung deposition from the Turbuhaler was similar for budesonide (mean $27.7 \%$ ) and for terbutaline sulphate (mean 27.0\%) [22]. Using the charcoal block technique, Borgström et al. [23] reported mean lung deposition values of $19 \%$ and $22 \%$ for two different doses of terbutaline sulphate in asthmatic patients, values broadly comparable to those found in the present study. In common with the AM-MDPI, drug delivery to the lungs from the Turbuhaler is also flow rate dependent; BorgStröm et al. [22] showed a reduction in lung deposition from $27.7 \%$ to $14.2 \%$ when the PIFR was reduced from 58 to $36 \mathrm{~L} \cdot \mathrm{min}^{-1}$. These data suggest that the lung deposition depends upon inhaled flow rate in a broadly similar manner for AM-MDPI and for Turbuhaler. Mean lung deposition for other DPIs used with optimal inhalation technique has ranged in scintigraphic studies from $11 \%$ [25] to $35 \%$ [26] of the metered dose.

Although whole lung deposition from the AM-MDPI varied significantly with inhaled flow rate, there was no corresponding change in regional lung deposition, as quantified by the $\mathrm{P} / \mathrm{C}$ ratio. The reason for this observation probably lies in the balance between the two opposing effects of increasing inspiratory flow, i.e. an increasing likelihood of particle impaction in large central airways per $s e$, but at the same time the generation of smaller particles which are more able to penetrate to the lung periphery. While the $\mathrm{P} / \mathrm{C}$ ratio detects expected changes in regional lung deposition brought about by changes in particle size for two aerosols inhaled under the identical conditions [27] the situation in the present study is compounded by the inhalation flow rate and particle size changing simultaneously. Previous scintigraphic studies involving other DPIs have also shown no change in $\mathrm{P} / \mathrm{C}$ ratio with a change in flow rate, despite a change in whole lung deposition $[9$, $10]$.

It is concluded that gamma scintigraphy has shown proof of concept in vivo for a novel dry powder inhaler, the ASTA Medica multi-dose dry powder inhaler, and has shown it to have one the highest lung deposition values observed for dry powder devices. The flow rate dependence of lung deposition was comparable to that for other "breath-actuated" dry powder inhalers. The pattern of regional lung deposition in the lungs was independent of flow rate, with good penetration to the lung periphery at all flow rates tested. Compared with the "gold standard" of the
Turbuhaler, the ASTA Medica multi-dose dry powder inhaler gave significantly greater lung deposition, when both devices were used optimally with maximal inspiratory effort, possibly because the lower resistance of the ASTA Medica multi-dose dry powder inhaler allowed higher inhaled flow rates to be achieved. This study was performed in healthy volunteers rather than asthmatic patients, but evidence suggests that whole lung deposition values from inhaler devices in patients are broadly similar to those in healthy subjects [25]. However, penetration of aerosol to the lung periphery is reduced in asthmatic patients, owing to the preferential deposition in central airways of the lungs [25]. The results presented in this study suggest that the ASTA Medica multi-dose dry powder inhaler should prove a valuable addition to the range of inhaler devices available for the maintenance therapy of asthma.

Acknowledgements. The authors are grateful to M. Pickford for valuable assistance in performing this study.

\section{References}

1. Clark AR. Medical aerosol inhalers: past, present and future. Aerosol Sci Technol 1995; 22: 374-391.

2. Newman SP, Hollingworth A, Clark AR. Effect of different modes of inhalation on drug delivery from a dry powder inhaler. Int J Pharm 1994; 102: 127-132.

3. Berner B, Fyrnys B, de Boer A, Göttenhauer W, WolfHeuss E. Asta Medica multidose dry powder inhaler. In: Dalby RN, Byron PR, Farr SJ, eds. Respiratory Drug Delivery VI. Buffalo Grove, IL, USA, Interpharm Press, 1998; pp. 475-477.

4. Newman SP, Steed KP, Hooper G, Källén A, Borgström L. Comparison of gamma scintigraphy and a pharmacokinetic technique for assessing the pulmonary deposition of terbutaline sulphate delivered by pressurised metered dose inhaler. Pharm Res 1995; 12: 231-236.

5. Newman SP. Scintigraphic assessment of therapeutic aerosols. Crit Rev Ther Drug Carrier Syst 1993; 10: 65109.

6. Newman SP. Scintigraphic assessment of pulmonary delivery systems. Pharm Tech 1998; 22: 78-94.

7. Quanjer PH, Tammeling GH, Cotes JE, Pedersen OF, Peslin R, Yernault J-C. Predicted values for spirometric lung function tests. Eur Respir J 1993; 6: Suppl. 16, 5-40. 
8. Thorsson L, Newman SP, Weisz A, Trofast E, Moren F. Nasal distribution of budesonide inhaled via a powder inhaler. Rhinology 1993; 31: 7-10.

9. Pitcairn GR, Lunghetti G, Ventura P, Newman SP. A comparison of the lung deposition of salbutamol inhaled from a new dry powder inhaler, at two inhaled flow rates. Int J Pharm 1994; 102: 11-18.

10. Pitcairn GR, Lim J, Hollingworth A, Newman SP. Scintigraphic assessment of drug delivery from the Ultrahaler dry powder inhaler. J Aerosol Med 1997; 10: 295-306.

11. Newman SP. Characteristics of radiolabelled versus unlabelled formulations. J Aerosol Med 1996; 9 (Suppl. 1): S37-S47.

12. Pitcairn GR, Newman SP. Tissue attenuation corrections in gamma scintigraphy. J Aerosol Med 1997; 10: 187-198.

13. Newman SP, Clark SR, Talaee N, Clarke SW. Pressurised aerosol deposition in the human lung with and without an "open" spacer. Thorax 1989; 44: 706-710.

14. Partridge MR, Woodcock AA, Sheffer AL, Wanner A, Rubinfeld A. Chlorofluorocarbon-free inhalers: are we ready for the change?. Eur Respir J 1998; 1: 1006-1008.

15. Keeley D, Rees J. New guidelines on asthma management. BMJ 1997; 314: 315-316.

16. British Asthma Guidelines Coordinating Committee. British guidelines on asthma management: 1995 review and position statement. Thorax 1997; 52: S1-S24.

17. Selroos O, Pietinalho A, Riska H. Delivery devices for inhaled asthma medication. Clin Immunother 1996; 6: 273299.

18. Pauwels R, Newman SP, Borgström L. Airway deposition and airway effects of antiasthma drugs delivered from metered dose inhalers. Eur Respir J 1997; 10: 2127-2138.

19. Snell NJC, Ganderton D. Assessing lung deposition of inhaled medications. Respir Med 1999; 93: 123-133.
20. Barnes PJ, Pedersen S, Busse WW. Efficacy and safety of inhaled corticosteroids: new developments. Am J Respir Crit Care Med 1998; 157: S1-S53.

21. Newman SP, Morén F, Trofast E, Talaee N, Clark SW. Deposition and clinical efficacy of terbutaline sulphate from Turbuhaler, a new multi-dose powder inhaler. Eur Respir J 1989; 2: 247-252.

22. Thorsson L, Edsbäcker S, Conradson T-B. Lung deposition of budesonide from Turbuhaler is twice that from a pressurised metered dose inhaler. Eur Respir J 1994; 7: 1839-1844.

23. Borgström L, Bondesson E, Morén F, Trofast E, Newman SP. Lung deposition of budesonide inhaled via Turbuhaler: a comparison with terbutaline sulphate in normal subjects. Eur Respir J 1994; 7: 69-73.

24. Borgström L, Derom E, Stahl E, Wahlin-Boll E, Pauwels $\mathrm{R}$. The inhalation device influences lung deposition and bronchodilating effects of terbutaline. Am J Respir Crit Care Med 1996; 153: 1636-1640.

25. Melchor R, Biddiscombe MF, Mak VHF, Short MD, Spiro SG. Lung deposition patterns of directly labelled salbutamol in normal subjects and in patients with reversible airways obstruction. Thorax 1993; 48: 506-511.

26. Warren SJ, Taylor G. Effect of inhalation flow profiles on the deposition of radiolabelled BDP from a novel dry powder inhaler (Clickhaler), a conventional metered dose inhaler and MDI plus spacer. In: Dalby RN, Byron PR, Farr SJ, eds. Respiratory Drug Delivery VI. Buffalo Grove, IL, USA, Interpharm Press, 1998; pp. 453-455.

27. Newman SP, Hirst PH, Pitcairn GR, Clark AR. Understanding regional lung deposition in gamma scintigraphy. In: Dalby RN, Byron PR, Farr SJ, eds. Respiratory Drug Delivery VI. Buffalo Grove, IL, USA, Interpharm Press, 1998; pp. 9-15. 